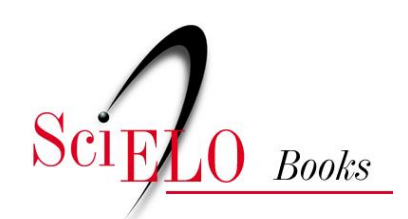

\title{
7. Reservatórios do Trypanosoma cruzi e sua relação com os vetores
}

\author{
André Luiz Rodrigues Roque \\ Ana Maria Jansen
}

\section{SciELO Books / SciELO Livros / SciELO Libros}

ROQUE, ALR., and JASEN, AM. Reservatórios do Trypanosoma cruzi e sua relação com os vetores. In: GALVÃO, C., org. Vetores da doença de chagas no Brasil [online]. Curitiba: Sociedade Brasileira de Zoologia, 2014, pp. 75-87. Zoologia: guias e manuais de identificação series. ISBN 978-85-9820309-6. Available from SciELO Books $<\underline{\text { http://books.scielo.org }>\text {. }}$

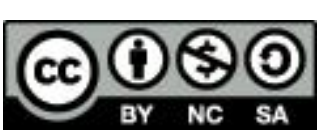

All the contents of this chapter, except where otherwise noted, is licensed under a Creative Commons Attribution-Non Commercial-ShareAlike 3.0 Unported.

Todo o conteúdo deste capítulo, exceto quando houver ressalva, é publicado sob a licença Creative Commons Atribuição Uso Não Comercial - Partilha nos Mesmos Termos 3.0 Não adaptada.

Todo el contenido de este capítulo, excepto donde se indique lo contrario, está bajo licencia de la licencia Creative Commons Reconocimento-NoComercial-CompartirIgual 3.0 Unported. 


\title{
7. Reservatórios do Trypanosoma cruzi e sua relação com os vetores
}

\author{
(André Luiz Rodrigues Roque \& Ana Maria Jansen)
}

"A natureza e os livros pertencem apenas aos olhos que os veem..." (Ralph Waldo Emerson)

O Trypanosoma cruzi, agente etiológico da Tripanosomíase Americana (doença de Chagas em humanos) é um protozoário flagelado pertencente à ordem Kinetoplastida, família Trypanosomatidae. Os kinetoplastídeos são organismos eucariotos muito antigos, provavelmente dos primeiros a divergirem das linhagens celulares eucarióticas ancestrais, e são assim classificados por possuírem uma mitocôndria única, rica em DNA (kDNA), denominada cinetoplasto. Dentro dos kinetoplastídeos, os membros da família Trypanosomatidae possuem um flagelo único e todos são parasitos de vertebrados, invertebrados ou plantas. Além do gênero Trypanosoma, essa família inclui ainda os gêneros Leishmania, Phytomonas, Endotrypanum, Leptomonas, Herpetomonas, Crithidia e Blastocrithidia, os quais estima-se que estejam filogeneticamente separados há aproximadamente 300 milhões de anos, data que coincide com o aparecimento dos primeiros vertebrados (Stevens et al. 2001).

Sugere-se que $T$. cruzi teve sua origem entre 100-80 milhões de anos atrás, em um super-continente ao Sul do planeta, formado pela América do Sul, Antártica e Austrália, que permaneceu unido após separação da África. Seus primeiros hospedeiros foram mamíferos das ordens Marsupialia e Xenarthra, que compunham a mastofauna autóctone. A transmissão teria sido garantida pela predação de outros mamíferos infectados (via oral) ou pelo contato de lesões, mucosa ou mesmo ingestão de material de glândula anal de marsupiais didelfídeos infectados, uma vez que essas glândulas podem manter o ciclo de multiplicação extracelular do T. cruzi e eliminar as formas metacíclicas infectivas (Deane et al. 1984, Schofield 2000). O panorama na América do Sul permaneceu inalterado até a entrada dos primeiros roedores caviomorfos e primatas provenientes da África ( 35 milhões de anos atrás), o que representa a primeira de várias ondas migratórias subseqüentes que resultaram na diversificação faunística encontrada atualmente em toda região (Flynn \& Wyss 1998). Assim, marsupiais e xenartras podem ser considerados como os hospedeiros mais antigos de $T$. cruzi (Briones et al. 1999, Stothard et al. 1999, Buscaglia \& Di Noia 2003). Posteriormente, o T. cruzi foi se adaptando aos novos hospedeiros na medida em que estes foram chegando na América do Sul: inicialmente roedores e primatas, e mais tarde morcegos e carnívoros. Esta variedade de hospedeiros que passou a fazer parte do ciclo de transmissão do T. cruzi exerceu diferentes pressões seletivas sobre este parasito, o que resultou na imensa variedade de subpopulações que conhecemos hoje e que apresentam importantes diferenças biológicas e moleculares. Estas diferenças são tão expressivas que alguns autores já propuseram a divisão de T. cruzi em duas espécies. Para facilitar a compreensão, adotaremos aqui o consenso aprovado por especialistas da área que reconhece dois genótipos principais TCl e TCII, além de um grupo de sub-populações do parasito que não se enquadram dentro destes dois genótipos e que são denominados como Z3 (zimodema 3) (Anonymous 1999). 
É proposto que a história co-evolutiva do T. cruzi com seus hospedeiros mamíferos seja bem mais antiga que a aquisição de hábitos hematofágicos pelos triatomíneos vetores (Schofield \& Galvão 2009). Apesar da origem dos seus ancestrais reduvídeos datar de aproximadamente 230 milhões de anos, a grande maioria das suas subfamílias é composta de insetos predadores e, até o momento, apenas duas espécies fósseis supostamente hematofágicas foram encontradas (Ponair Jr. 2005, 2013). O ciclo digenético como vemos hoje, envolvendo triatomíneos e mamíferos, parece ter se iniciado apenas após a aquisição dos hábitos hematofágicos pelos triatomíneos há aproximadamente 5 milhões de anos, seguida da adaptação do parasito ao tubo digestivo destes vetores (Carcavallo et al. 1999; Schofield 2000).

Atualmente, esse parasito é encontrado circulando na natureza entre mais de uma centena de espécies de mamíferos distribuídos em sete diferentes ordens e dezenas de espécies de vetores (Noireau et al. 2009). As aves e os vertebrados de sangue frio são refratários ao parasito. Os ciclos de transmissão desse parasito encontram-se em todas as regiões fitogeográficas do país, nos mais diversos nichos ecológicos contribuindo, cada tipo de ecótopo, com focos de transmissão que apresentam distintos perfis epidemiológicos, os quais se caracterizam por serem multivariáveis e complexos (PAHO 2009). Como sabemos, a doença de Chagas é uma manifestação clínica que pode decorrer da infecção de T. cruzi no ser humano, cuja transmissão ocorre, na grande maioria das vezes, por triatomíneos vetores. Outras vias de infecção são a oral (pela ingestão de alimento contaminado com as formas infectivas do parasito), congênita, por transfusão sanguínea ou transplante de órgãos.

Os triatomíneos transmitem o parasito apenas se estiverem infectados e isto acontece quando eles se alimentam sobre um dos numerosos hospedeiros mamíferos infectados e ingerem, juntamente a seu sangue, as formas tripomastigotas do parasito. No trato digestivo dos triatomíneos, os parasitos diferenciam-se em formas epimastigotas (capazes de multiplicar) e, posteriormente, em formas tripomastigotas metacíclicas na porção final do intestino, as quais são eliminadas com as fezes do triatomíneo. A infecção dos mamíferos ocorre quando estes entram em contato com as formas infectivas do parasito contidas nas fezes do triatomíneo. Esse contato ocorre pelas mucosas ou através de lesão preexistente ou resultante da picada do barbeiro. A via oral, ou seja, a ingestão das formas infectivas do parasito, ocorre quando o animal coça com a boca o local do seu corpo onde estão depositadas essas fezes, ingere alimentos contaminados com o parasito ou preda triatomíneos ou outros mamíferos infectados.

Desde a descoberta do T. cruzi há um século, diversos pesquisadores buscaram conhecer quais as espécies de mamíferos que eram fontes de infecção para o triatomíneo e, consequentemente, para o ser humano e/ou animais domésticos. As numerosas espécies de animais silvestres que foram encontradas infectadas por T. cruzi foram denominadas "reservatórios naturais" (Barretto \& Ribeiro 1979). A continuação destes estudos mostrou que no caso de um parasito multi-hospedeiro como o T. cruzi, não apenas uma, mas diversas espécies de mamíferos poderiam ser apontadas como fonte de infecção ao vetor em um determinado local. Passou-se a entender que estes mamíferos apresentam diferenças na sua importância como fonte de infecção para o triatomíneo vetor e que uma mesma espécie de mamífero pode desempenhar distintos papéis na manutenção do parasito em diferentes localidades. Dentro desse enfoque, passamos a considerar como reservatório não apenas uma única espécie de mamífero infectado em uma determinada localidade, mas 
um sistema que pode incluir uma ou mais espécies de mamíferos responsáveis pela manutenção do parasito na natureza. Em cada sistema ecológico, as espécies desempenham papéis diferentes na manutenção do parasito, o que significa que o papel de cada componente na manutenção do parasito deve sempre ser considerado único dentro de uma determinada escala espaço-temporal.

O perfil da infecção por T. cruzi em qualquer espécie de mamífero é determinado por fatores relacionados ao hospedeiro (espécie, sexo, idade, padrão comportamental), ao parasito (tempo de geração, estratégias de dispersão, características bioquímicas e moleculares das subpopulações) e ao ambiente (stress, coinfecções, disponibilidade de recursos) onde ocorre a interação. Consideramos como reservatórios mantenedores aqueles capazes de se infectar e manter a infecção por um determinado parasito. Reservatórios amplificadores são aqueles que apresentam um perfil de infecção que favorece a transmissibilidade desse parasito.

No caso do T. cruzi, a transmissibilidade de uma espécie de mamífero ao vetor é garantida quando este mamífero apresenta formas circulantes do parasito no sangue. Este atributo é comprovado pela visualização de parasitos no sangue dos mamíferos por técnicas parasitológicas de exame a fresco, hemocultivo ou xenodiagnóstico. Já a transmissão do parasito entre duas espécies de mamíferos (presa-predador) pode ser garantida mesmo na ausência de formas circulantes do parasito no sangue, visto que formas amastigotas presentes nos tecidos do mamífero predado, também podem ser fonte de infecção. O diagnóstico da infecção por T. cruzi apenas por exames indiretos, como os testes sorológicos, apontam para a exposição do animal ao agente etiológico, mas isso não reflete sua transmissibilidade para os triatomíneos ou mesmo a outros mamíferos. Animais sorologicamente positivos indicam que foram expostos ao T. cruzi, são hospedeiros desse parasito, mas não necessariamente são importantes para a manutenção do parasito na natureza, ou seja, não são obrigatoriamente reservatórios do parasito. Assim, uma investigação epidemiológica em hospedeiros silvestres de $T$. cruzi deve incluir, obrigatoriamente, uma amostragem representativa das espécies de mamíferos mais abundantes na área e uma ampla abordagem metodológica que inclua diagnóstico da infecção por exames parasitológicos diretos e indiretos (Roque et al. 2008). $O$ direcionamento das coletas a algumas espécies de mamíferos ou a ambientes peridomiciliares, que não são representativos de toda a área, resulta em que as espécies mais comuns àquele habitat sejam apontadas como reservatórios do parasito. Desta forma, mamíferos sinantrópicos como o Rattus rattus, Mus musculus e os gambás do gênero Didelphis spp. são frequentemente encontrados infectados em diversos estudos, mas nem sempre representam as espécies de mamíferos mais importantes para a manutenção do parasito naquela área.

Diante desta complexidade, fica claro que muito mais do que um sistema linear, é preciso entender os ciclos de transmissão do T. cruzi na natureza como uma teia, uma rede dinâmica de transmissão do parasito por diferentes vias. Nesta rede de transmissão estão incluídos mamíferos de diferentes táxons e diferentes espécies de triatomíneos, os quais apresentam particularidades que se refletem na capacidade destes em transmitir o T. cruzi. É neste contexto que apresentamos alguns desses mamíferos capazes de manter o parasito na natureza (portanto, potenciais reservatórios), os vetores a estes associados e alguns dos estudos mais relevantes em cada uma das sete ordens de mamíferos responsáveis pela manutenção do T. cruzi na natureza. 


\section{Ordem Marsupialia}

Representante da nossa fauna autóctone, a ordem Marsupialia apresenta sua maior diversidade de espécies no continente Australiano, enquanto apenas uma família é reconhecida nas Américas, a Didelmorphidae. Seus ancestrais são tidos como os mais antigos hospedeiros do T. cruzi. O gênero Didelphis (Figura 7.1) é aquele com maior dispersão no continente, ocorrendo do sudeste do Canadá ao sul da Argentina, sendo o mamífero reconhecido por muitos como o mais importante reservatório do parasito.

A sua ampla distribuição se deve principalmente a sua impressionante adaptabilidade a diferentes nichos ecológicos, principalmente a ambientes com elevado grau de ação antrópica. Esses animais podem colonizar forros das casas e outros abrigos do domicílio e peridomicílio, e sobrevivem alimentando-se de restos alimentares do ser humano. Estas características fazem com que as espécies de Didelphis sejam atualmente reconhecidas como sinantrópicas e sua presença é forte indicador de degradação ambiental por

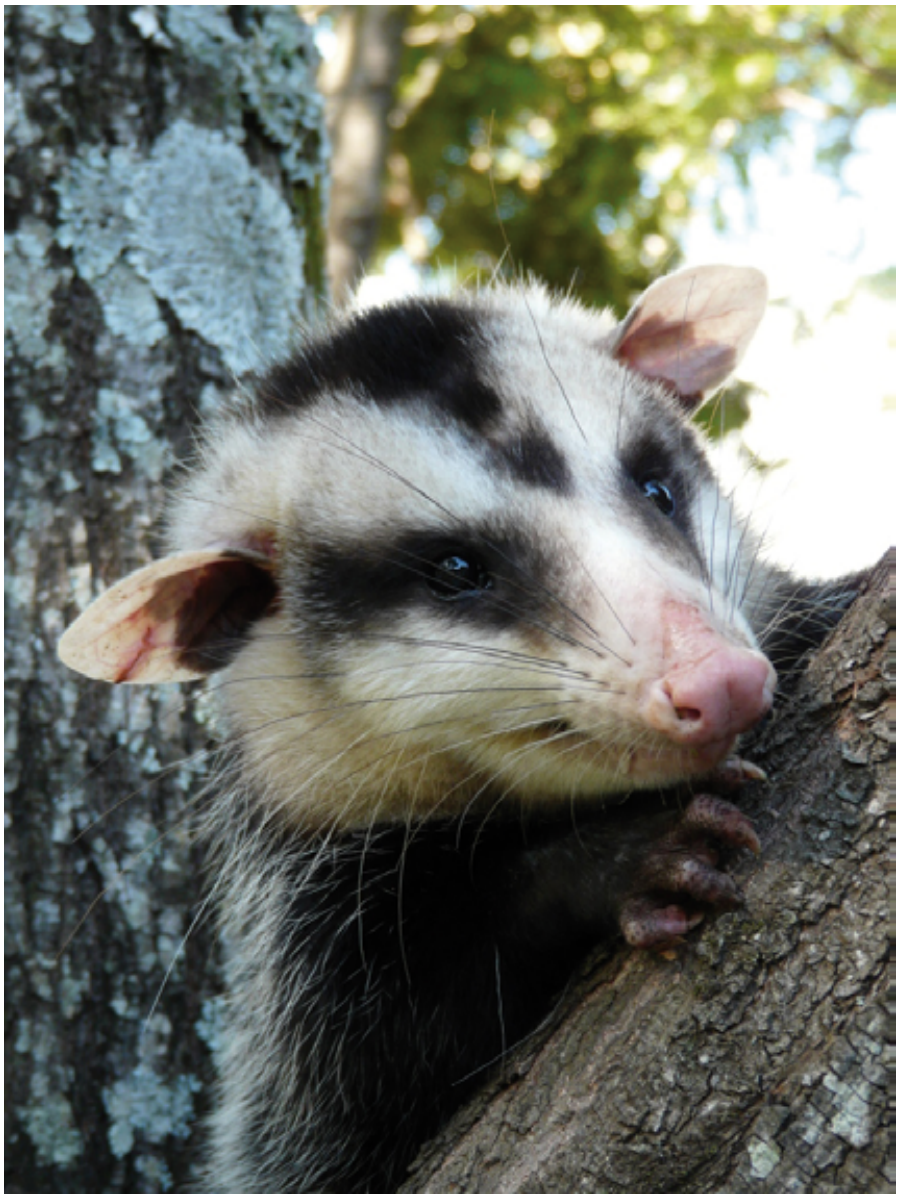

Figura 7.1: Didelphis albiventris proveniente de São Borja, RS. influência humana (Olifiers et al. 2005).

O perfil de infecção desses animais por T. cruzi apresenta uma característica que os tornam únicos quando comparados aos demais hospedeiros do parasito: a capacidade de atuar como hospedeiros e vetores ao mesmo tempo. Quando infectados, alguns parasitos alcançam a glândula de cheiro desses animais e atingem seu lúmen. Na luz da glândula, as formas tripomastigotas sanguícolas se diferenciam em formas epimastigotas e multiplicam-se através de divisão binária, antes de se diferenciarem em formas tripomastigotas metacíclicas que são as formas infectivas eliminadas juntamente à secreção dessa glândula (Deane et al. 1984). Essa etapa simula o ciclo de multiplicação do parasito encontrado no trato digestivo dos triatomíneos e ocorre simultaneamente ao ciclo multiplicativo intracelular na forma amastigota, que acontece nos diversos tecidos do animal. A competência vetorial dessas glândulas e, portanto, sua importância epidemiológica, permanece desconhecida, apesar da alta taxa de metaciclogênese (até 50\%) sugerir que esta pode ser uma eficiente via de dispersão do parasito. Além dos Didelphis spp., o ciclo de multiplicação extracelular do parasito em glândulas de cheiro também já foi demonstrado em indivíduos de Lutreolina crassicaudata experimentalmente infectados (Steindel \& Pinto 1988).

Didelphis spp. são nômades, solitários (principalmente os machos), excelentes escaladores e seu refúgio principal são buracos e folhagens de árvores. Em seus refúgios são comumente encontrados triatomíneos do gênero Rhodnius, representados por 19 espécies, todas normalmente 
associadas a palmeiras e ocos de árvores. Panstrongylus megistus e Microtriatoma trinidadensis são outras espécies de triatomíneos que podem ser encontrados em ninhos de Didelphis spp. Sua importância como reservatório varia no tempo e espaço, como observado nas taxas de infecção de $D$. aurita que variaram entre 11 e $90 \%$ entre animais coletados em diferentes localidades no estado do Rio de Janeiro (Fernandes et al. 1999). Além da via vetorial, seu hábito onívoro favorece que esse mamífero possa adquirir a infecção também por via oral, pela ingestão de triatomíneos ou predação de pequenos mamíferos infectados.

Estudos experimentais mostraram ausência de transmissão neonatal do parasito em $D$. aurita e que estes são capazes de manter infecções estáveis por subpopulações do genótipo TCI do parasito e controlar ou até mesmo eliminar subpopulações do genótipo TCII. No entanto, esses trabalhos foram realizados com uma pequena amostragem de isolados que não são representativos da heterogeneidade observada entre as sub-populações do genótipo TCII (Jansen et al. 1991). De fato, embora esses animais estejam mais comumente relacionados a TCl, o genótipo TCII também tem sido isolado. Apesar de frequentemente associados ao ambiente arbóreo, Didelphis spp. deslocam-se por todos os estratos vegetais e podem servir de fonte de infecção a triatomíneos terrestres ou ainda servir de elo entre ciclos de transmissão independentes, uma vez que podem adquirir a infecção ao predar um Panstrongylus geniculatus no solo e servir de fonte de infecção a um Rhodnius robustus na copa de uma palmeira.

Na natureza, as cuícas Philander frenatus e $P$. opossum também podem assumir um papel importante na manutenção e infecção de triatomíneos, uma vez que são encontradas altas prevalências de infecção com hemocultivos positivos que podem chegar a 80\%. Ao contrário de D. aurita, a infecção experimental de $P$. frenatus resultou em altas parasitemias e altos títulos de anticorpos quando infectadas por ambos os genótipos TCl e TCII do parasito (Legey et al. 1999). O perfil das infecções experimentais de $D$. aurita e $P$. frenatus mostra que essas espécies podem ser responsáveis por distintas pressões seletivas para as sub-populações de $T$. cruzi e, assim, desempenhar papéis diferentes na transmissão do parasito na natureza.

Monodelphis domestica é outra espécie de marsupial comumente encontrada infectada por $T$. cruzi, tendo sido apontada como o principal reservatório de T. cruzi numa área de surto de doença de Chagas Aguda por via oral no Ceará (Roque et al. 2008). Esse pequeno marsupial é terrestre e pode estar envolvido em ciclos de transmissão que envolvam espécies de Panstrongylus como vetores. Caluromys lanatus, Lutreolina crassicaudata, Marmosa sp., Metachirus nudicaudatus e Monodelphis brevicaudata são outras espécies de marsupiais já encontradas naturalmente infectadas por T. cruzi.

\section{Ordem Xenarthra}

Tatus, preguiças e tamanduás são os principais representantes dessa ordem que é autóctone das Américas e compreende, ao lado dos marsupiais, os mais antigos hospedeiros do Trypanosoma cruzi. A primeira descrição de reservatório silvestre desse parasito foi feita pelo próprio Carlos Chagas, em 1912, ao encontrar formas parasitárias semelhantes ao T. cruzi no tatu-galinha (Dasypus novemcinctus), o qual ele classificou como um "depositário do agente da tripanossomíase brasilei- 
ra no mundo exterior" (Chagas 1912). Em seus abrigos subterrâneos, tatus são normalmente associados a triatomíneos Panstrongylus geniculatus e alguns trabalhos apontam para uma associação entre esses hospedeiros e o genótipo TCII do parasito (Yeo et al. 2005). Apesar disso, esses animais já foram encontrados infectados por outros genótipos do parasito, $\mathrm{TCl}$ e a Z3, mostrando sua importância na manutenção de distintos ciclos de transmissão na natureza.

Os tatus apresentam vasta distribuição, sendo encontra-

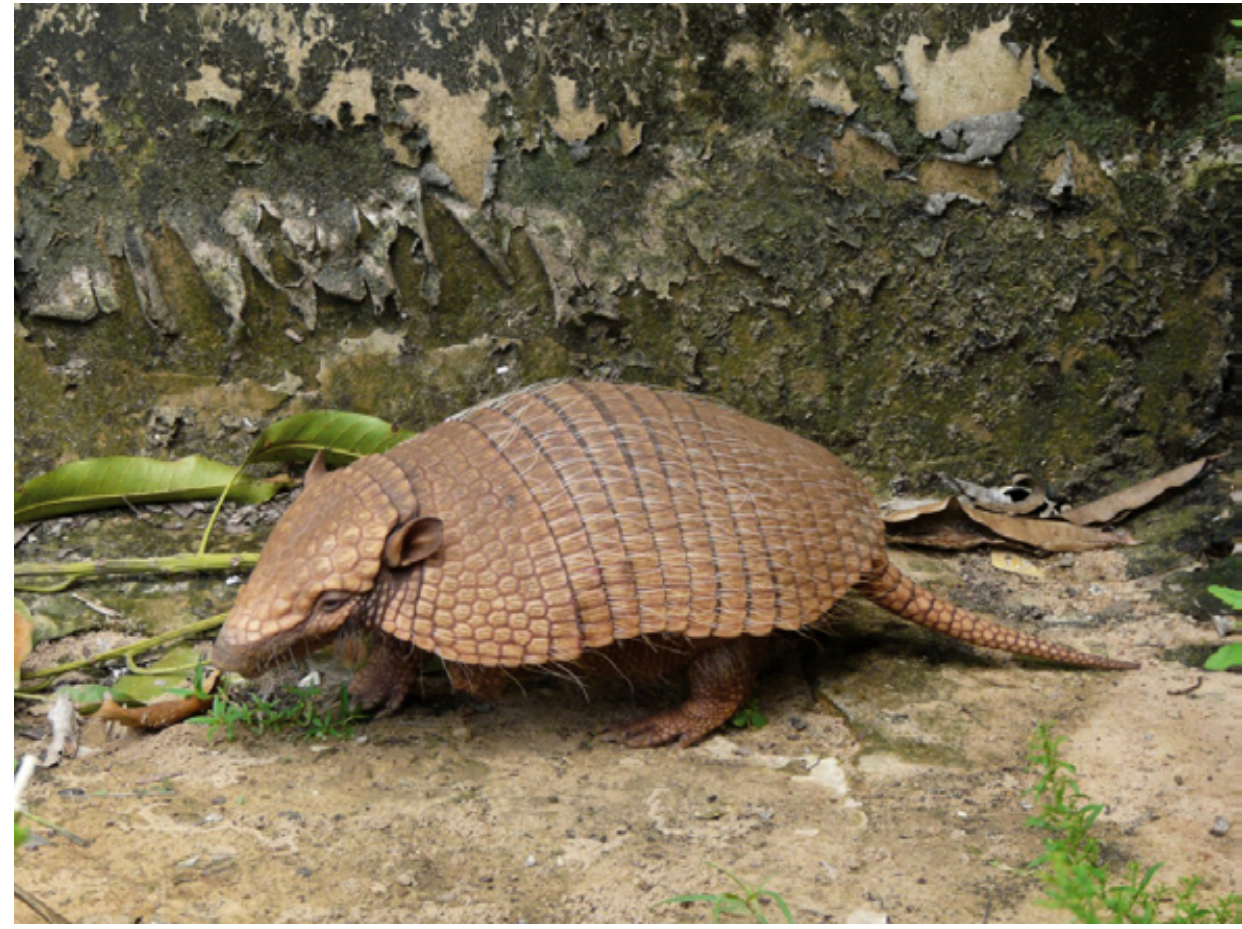

Figura 7.2: Euphractus sexcinctus proveniente de Axixá do Tocantins, TO. dos naturalmente infectados em prevalências de infecção que variam de 4 a $50 \%$ desde o sul dos Estados Unidos até o Uruguai. Na Guiana Francesa, Dasypus novemcinctus foram apontados como importante reservatório de T. cruzi, atrás apenas de Didelphis marsupialis (Raccurt 1996). Além do tatu-galinha, outras espécies já encontradas infectadas são o tatu-de-rabo-mole-pequeno (Cabassous unicinctus) e o tatu peba (Euphractus sexcinctus) (Figura 7.2). Importante ressaltar que em áreas rurais é comum o tatu peba invadir galinheiros a procura de ovos e/ou animais, aproximando-se desta forma do ambiente peridomiciliar e podendo infectar os triatomíneos que ali se encontrem.

Dentre os Xenarthras arborícolas, preguiças são geralmente associadas a triatomíneos dos gêneros Belminus, Panstrongylus e Rhodnius (Carcavallo et al. 1998) e algumas espécies como a preguiça-de-coleira (Bradypus torquatus) já foram encontradas naturalmente infectadas. Duas espécies de tamanduás, o tamanduá mirim (Tamandua tetradactyla) e o tamanduaí (Cyclops didactylus) também já foram apontados como hospedeiros naturais de T. cruzi.

A importância epidemiológica desses mamíferos é ainda maior se considerarmos que preguiças, tamanduás e tatus são caçados e consumidos em algumas áreas do país, como na região Amazônica, e que a manipulação da carcaça ou a ingestão da carne mal cozida de animais infectados podem constituir fontes de infecção para o ser humano.

\section{Ordem Rodentia}

Roedores não são autóctones das Américas e os primeiros animais (Hystricognathi -caviomorfos) chegaram com os primeiros primatas oriundos da África há cerca de 45 milhões de anos. A segunda fase de entrada de roedores nas Américas (Sciurognathi - cricetídeos) é bem mais recente e parece estar relacionada à diversificação dos roedores murídeos e cricetídeos na África e uma 
rota de migração que incluía um estabelecimento inicial na América do Norte. Após sua chegada, os roedores adaptaram-se bem e diversificaram-se em um grande número de espécies. Estas coIonizaram os mais diversos tipos de habitat, das florestas tropicais aos desertos, dos planaltos de elevadas altitudes às planícies alagadas, do ambiente silvestre ao ambiente urbano, além dos mais diversificados estratos naturais, podendo ser encontradas desde espécies fossoriais a espécies de hábitos semi-aquáticos e arborícolas.

Na natureza, os roedores formam a maior biomassa de mamíferos em qualquer ecótopo silvestre. Seus mais diversos microhabitats são muitas vezes divididos com triatomíneos, como os Triatoma spp., geralmente associados a refúgios rochosos terrestres e os Panstrongylus spp., associados a buracos no solo. Adultos do triatomíneo Eratyrus mucronatus são geralmente associados a ouriços (Coendu spp.) em árvores, embora as ninfas desse triatomíneo se alimentem exclusivamente em outros invertebrados. Um aspecto importante é que, dentre os mamíferos, roedores são os principais alvos de predação, o que possibilita a transmissão oral de $T$. cruzi. Sua importância epidemiológica fica evidente se considerarmos que muitas espécies, embora silvestres, frequentemente se aproximam e podem colonizar o ambiente peridomiciliar.

A infecção de roedores silvestres por $T$. cruzi é pouco reportada, o que reflete as limitações na metodologia de coleta dos animais, normalmente restrita a áreas domiciliares. Exemplo disso é que a maioria das descrições de infecção por $T$. cruzi em roedores ocorrem em Rattus rattus, espécie sinantrópica abundante na maioria das cidades brasileiras e normalmente associada a Triatoma rubrofasciata. Apesar de abundantes em muitos trabalhos, o diagnóstico da infecção em Mus musculus é pouco reportado. Outras espécies já encontradas naturalmente infectadas são: Agouti paca, Akodon sp., Bolomys lasiurus, Calomys expulsus, C. callosus, Cavia sp., Clyomys laticeps, Dasyprocta sp., Echymis chrysurus, E. dasytrix, Galea spixii, Holochilus brasiliensis, Kerodon rupestris, Nectomys squamipes, Octodon degus, Octodontomys sp., Oecomys mamorae Oligoryzomys stramineus, Oryzomys capito, O. scotti, Proechimys spp., Rhiphidomys macrurus, Sigmodon hispidus, e Tylomys mirae.

Mas sem dúvida, os roedores cuja participação nos ciclos de transmissão de T. cruzi mais empiricamente comprovados são os caviomorfos do gênero Thrichomys. Esse gênero compreende ao menos cinco espécies crípticas distribuídas no Pantanal, Cerrado e Caatinga brasileiros (Bonvicino et al. 2002). Thrichomys laurentius (Figura 7.3) foi encontrado com prevalências de infecção por hemocultivo que chegam a $44 \%$ em algumas localidades que compõem o Parque Nacional da Serra da Capivara, no Piauí (Herrera et al. 2005). Esses roedores também já foram encontrados infectados (100\% com sorologia

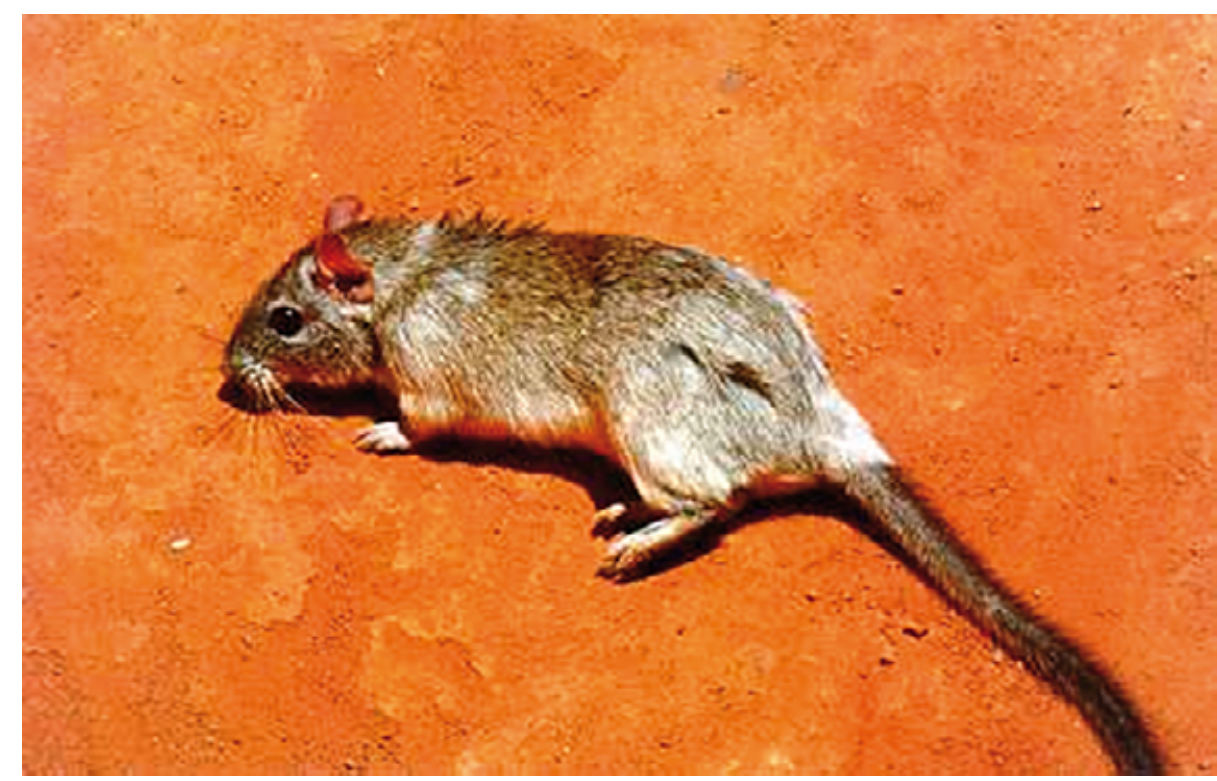

Figura 7.3: Thrichomys laurentius proveniente de São Raimundo Nonato, PI. 
positiva) em uma área de surto de doença de Chagas Aguda por via oral no Ceará (Roque et al. 2008). Thrichomys pachyurus, no Pantanal sul-matogrossense e T. apereoides, no Centro-Oeste do país também já foram encontrados infectados por T. cruzi e a infecção desses animais ocorre pelos três genótipos ( $\mathrm{TCl}$, TCll e Z3), incluindo o diagnóstico de infecção mista (TCl/Z3) de um T. pachyurus no Pantanal (Herrera et al. 2007).

Estudos experimentais mostraram que $T$. apereoides foram capazes de manter infecções estáveis por ambos genótipos TCI e TCII do parasito (Herrera et al. 2004). Outras duas espécies do gênero Thrichomys ( $T$. laurentius e T. pachyurus) também foram capazes de controlar e manter a infecção experimental por T. cruzi, apresentando parasitemias patentes, efetiva resposta imune humoral e importantes danos tissulares (Roque et al. 2005). Nesse caso, as diferenças observadas no padrão de infecção mostraram que $T$. laurentius foi mais resistente à infecção que T. pachyurus, expressado por mais baixas parasitemias e menores danos tissulares frente a todas as subpopulações do parasito estudadas. A diferença observada no curso da infecção experimental pode se refletir em diferente capacidade desses animais em atuarem como reservatórios em suas respectivas localidades.

Considerando os resultados de infecção experimental, a distribuição desses roedores na natureza e sua prevalência de infecção natural por T. cruzi, Thrichomys spp. podem atuar como (i) hospedeiros mantenedores, dada sua capacidade de manter parasitemias subpatentes por longos períodos; e (ii) hospedeiros amplificadores como demonstrado pelo longo período de parasitemia patente em condições experimentais e hemocultivo positivo em condições naturais (Roque et al. 2005).

Em última análise, vale ressaltar que os estudos envolvendo T. cruzi e caviomorfos mostraram que a antiguidade da relação parasito-hospedeiro não necessariamente evolui para uma interação harmônica, mas pode evoluir para uma que favoreça a transmissibilidade do parasita, independente das lesões que venha a causar no hospedeiro. No caso dos Thrichomys, esses roedores apresentam um dano cardíaco importante, o que certamente se reflete na sua capacidade de oxigenação dos tecidos. Isso significa que um roedor infectado teria diminuída sua habilidade de fugir dos predadores, predispondo-o a transmitir o parasito a outro mamífero que venha a predá-lo.

\section{Ordem Primata}

Um sagüi-estrela Callithrix penicilata foi o primeiro hospedeiro identificado por Carlos Chagas quando da descoberta do novo tripanosomatídeo em Lassance/MG, o qual ele batizou de Trypanosoma minasensis. Posteriormente, examinando os triatomíneos do local, Chagas encontrou flagelados que inferiu se tratar de formas intermediárias dos tripanossomos diagnosticados nos sagüis. Para confirmar essa hipótese, enviou alguns insetos infectados para que os mesmos fossem utilizados para infectar grupos de Callithrix jacchus mantidos em cativeiro, resultando na visualização de flagelados no sangue periférico dos sagüis, com morfologia completamente distinta do T. minansensis. Era descoberto o Trypanosoma cruzi.

Desde então, diferentes espécies de primatas neotropicais incluídas nas famílias Cebidae (micos) e Callitrichidae (sagüis) são comumente encontradas naturalmente infectadas por T. cruzi. Endêmicos 
das Américas, esses primatas ocupam distintos estratos arbóreos e apresentam hábitos alimentares variados, incluindo espécies que se alimentam de invertebrados e pequenos mamíferos, o que favorece a transmissão de $T$. cruzi pela via oral. Seu refúgio noturno em ocos de árvores, muitas vezes compartilhado com triatomíneos, possibilita a infecção vetorial desses animais.

A prevalência de infecção em primatas varia entre $4-88 \%$, podendo ser bastante elevada

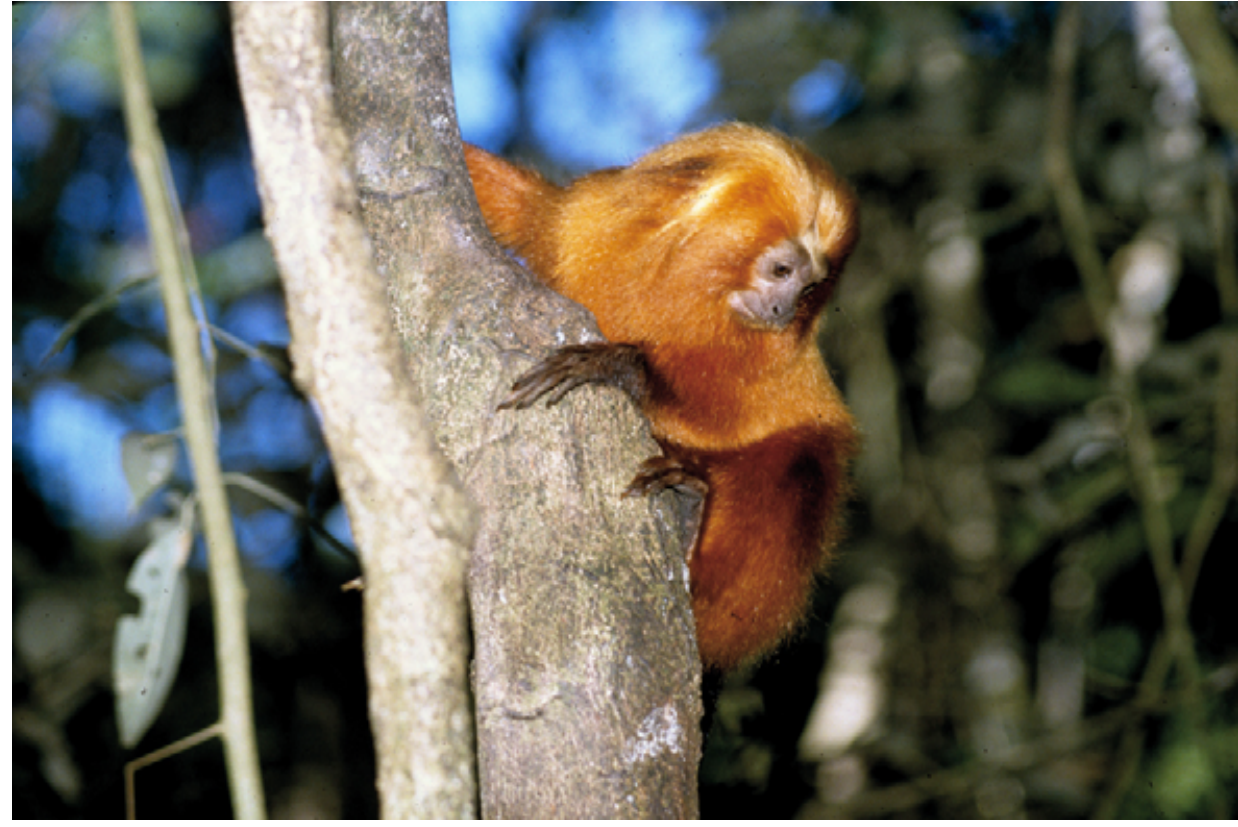

Figura 7.4: Leonthopitecus rosalia proveniente de Silva Jardim, RJ. em micos leões. Tanto a prevalência da infecção, quanto a transmissibilidade do parasito (avaliada por hemocultivo) variam de acordo com sexo, idade, espécie, co-infecção com outros parasitos, fitofisionomia e local de origem da população analisada. A associação entre a presença de infecção por nematóides trichostrongilídeos e a prevalência de hemocultivos positivos, por exemplo, já foi observada em mico-leões das espécies Leonthopitecus rosalia e L. chrysomelas (Monteiro et al. 2007).

Em Poço das Antas, L. rosalia (Figura 7.4) é um importante reservatório do parasito e apresenta elevada prevalência de infecção por hemocultivo (46\%), sendo que essa prevalência varia entre os diversos grupos familiares de micos (Lisboa et al. 2000). Apenas o genótipo TCll do parasito foi isolado desses animais, apesar do genótipo TCI também circular no local em outras espécies de mamíferos não primatas. Essas taxas de infecção são completamente distintas de outras áreas adjacentes à Reserva, onde a mesma espécie $L$. rosalia apresenta baixa prevalência de infecção por T. cruzi, reforçando o caráter focal de manutenção do parasito na natureza. A infecção de primatas não se restringe ao genótipo TCII do parasito e muitas espécies já foram encontradas naturalmente infectadas pelo genótipo TCI do parasito em diferentes regiões do país, desde a Mata Atlântica até a região Amazônica (Lisboa et al. 2006). O genótipo $Z 3$ do parasito também já foi descrito em primatas, mas esse achado ainda é restrito à região Amazônica (Marcili et al. 2009).

Um fator importante no estudo de primatas neotropicais é que muitos deles se encontram ameaçados de extinção e são submetidos a programas de conservação, como é o caso do mico-leão-dourado. Esses programas frequentemente incluem intercâmbio, translocação e re-introdução de animais, sem que se considere a prevalência e perfil de infecção por parasitos, como o T. cruzi. Dado o caráter focal de transmissão do parasito, programas como esse podem desencadear na introdução de mamíferos infectados e promover o estabelecimento de novos ciclos de transmissão.

Os estudos experimentais em primatas neotropicais (Cebus sp. Callithrix sp. e Saimiri sp.) e africanos (Macaca mulatta) mostram que a infecção por T. cruzi nesses mamíferos apresenta muitos pontos em comum com a Doença de Chagas, tais como a baixa frequência de alterações cardioló- 
gicas, rara ocorrência de síndromes megas, e modificações sistêmicas. Estudos longitudinais em mico leões mostram uma única alteração sistêmica associada à infecção por T. cruzi: maior média de Proteína Total sérica nos animais infectados, alteração compatível com a hipergamaglobulinemia provocada pela infecção por $T$. cruzi. As alterações eletrocardiográficas observadas foram baixa voltagem de onda T, baixa voltagem de onda R e alta voltagem de onda V3S, todas em DII (Monteiro et al. 2006).

\section{Ordem Carnivora}

Carnívoros silvestres como o quati (Nasua nasua) (Figura 7.5), a irara (Eira barbara) e o cachorro-do-mato (Cerdocyon thous) já foram encontrados naturalmente infectados por T. cruzi. Alguns desses, como o quati e a irara são encontrados tanto no solo quanto em copa de árvores, favorecendo a dispersão do parasito entre diferentes estratos arbóreos. Esses mamíferos apresentam uma importante biomassa corporal e grande área de deslocamento, aspectos importantes para a dispersão de parasitos. Carnívoros de médio e grande porte são conhecidos como predadores de topo de cadeia e sua alimentação normalmente inclui outros mamíferos menores que podem estar infectados por T. cruzi. Assim, embora a transmissão vetorial também ocorra, a via mais comum de infecção desses animais, assim como de qualquer outro predador na natureza, parece ser a via oral pela ingestão de mamíferos infectados.

Na região do Pantanal, os quatis parecem ser os principais reservatórios e amplificadores das populações parasitárias do T. cruzi, tendo sido encontrados infectados por todos os genótipos do parasito (TCl, TCll e Z3), em infecções simples ou mistas com todas as associações possíveis de genótipos (TCl e TCII, TCl e Z3, TCII e Z3). O acompanhamento de quatis re-capturados mostra que a infecção por $T$. cruzi pode apresentar altas parasitemias e ser mantida por longo tempo. Nessa região, esses animais apresentam elevada abundância relativa, o que reforça ainda mais sua importância como reservatório amplificador das populações parasitárias nessa região (Herrera et al. 2008b).

O genótipo Z3 do parasito também já foi isolado de um furão ( $G a$ lictis vitatta) na Mata Atlântica do estado do Rio de Janeiro (Lisboa et al. 2009). O zorrilho (Conepatus chinga) na Argentina e os guaxinins (Procyon lotor) e raposas-cinzentas (Urocyon

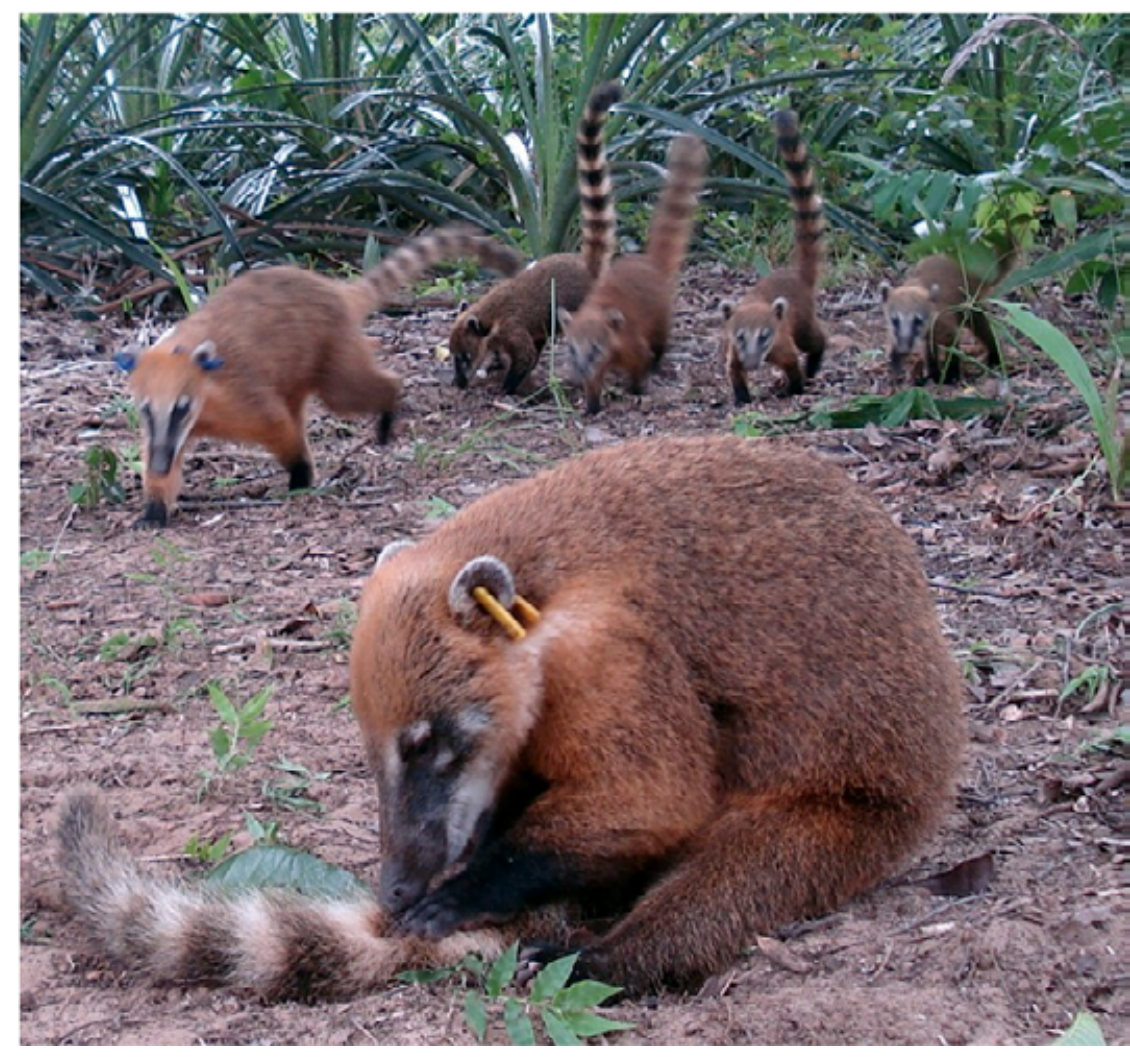

Figura 7.5: Nasua nasua proveniente da fazenda Nhumirim, na região da Nhecolândia, MS. 
cinereoargenteus) na América Central e sul dos Estados Unidos são outros exemplos de carnívoros silvestres frequentemente encontrados infectados por T. cruzi.

Cães e gatos são carnívoros domésticos que representam alguns dos primeiros hospedeiros do T. cruzi descritos por Carlos Chagas. De fato, um gato em Lassance/MG foi o primeiro hospedeiro no qual Carlos Chagas diagnosticou o parasito no sangue, enquanto cães estiveram entre os primeiros modelos experimentais utilizados. Diversos estudos já demonstraram que ambos podem atuar como importantes reservatórios do parasito, mas assim como acontece com os demais taxons de mamíferos, sua importância no ciclo de transmissão varia de uma para outra região. Na região do Chaco Argentino, tanto cães quanto gatos são epidemiologicamente importantes e descritos como altamente infectivos aos vetores (Gurtler et al. 2007). Perfil semelhante foi encontrado na Venezuela, onde ambos os genótipos TCl e TCII do parasito circulam entre os cães (Crisante et al. 2006). Transmissão ativa, incluindo cães sintomáticos, foi observada no sul dos Estados Unidos (Kjos et al. 2008).

Situação oposta é observada no Brasil, onde apesar de expostos ao parasito (evidenciado pela presença de anticorpos anti-T. cruzi no soro dos animais), raramente são encontrados cães sintomáticos ou é obtido o isolamento de parasitos (Roque \& Jansen 2008). Nossa experiência inclui mais de 800 cães examinados em diferentes regiões do país, como a bacia Amazônica e as regiões Nordeste e Sudeste do país e o perfil de infecção nos cães em todas essas regiões mostrou-se bastante semelhante.

O diagnóstico da infecção por T. cruzi em animais domésticos aponta para a presença do parasito em áreas onde esses animais circulam. Baseado nesse entendimento e no perfil de infecção desses animais, estudos conduzidos na Argentina, Venezuela, México, Estados Unidos e Brasil recomendam a utilização desses animais como sentinelas em programas de vigilância e controle da doença (Roque \& Jansen 2008). Nesse caso, o conhecimento da prevalência de infecção por $T$. cruzi nesses hospedeiros pode auxiliar no direcionamento de ações de educação e vigilância ainda antes do aparecimento dos primeiros casos humanos.

\section{Ordem Chiroptera}

Os morcegos são comumente encontrados infectados por diversos tripanosomatídeos, dentre os quais o Trypanosoma cruzi. Seus refúgios incluem ocos de árvores, folhas de bananeiras e forros de habitações humanas e construções rurais. Estes mamíferos podem ser importantes reservatórios do parasito, visto que em determinadas áreas são abundantes, adaptam-se bem ao domicílio humano e podem apresentar elevadas prevalências de infecção.

A infecção ocorre por diferentes vias, mas a transmissão oral decorrente da ingestão de triatomíneos infectados certamente representa um papel importante. Morcegos dos gêneros Carollia, Artibeus e Molossus adquiriram a infecção ao se alimentarem de Rhodnius prolixus experimentalmente infectados (Thomas et al. 2007). Já Phyllostomus hastatus, espécie com hábitos alimentares generalistas, adquiriu a infecção ao predar um camundongo infectado (Thomas et al. 2007). Nesse sentido, vale mencionar que mesmo morcegos predominantemente frugívoros como Artibeus sp. (Figura 7.6), Carollia sp. e Glossophaga sp. frequentemente alimentam-se de insetos e podem infectar-se por essa 
via (Gardner 1977). Apesar de se alimentarem de sangue de mamíferos que podem conter formas infectivas do parasito, a infecção em morcegos hematófagos raramente é documentada. Esta particularidade pode ser explicada pelo fato desses morcegos alimentarem-se preferencialmente em bovinos e equinos, dois grupos de mamíferos raramente associados à infecção por T. cruzi.

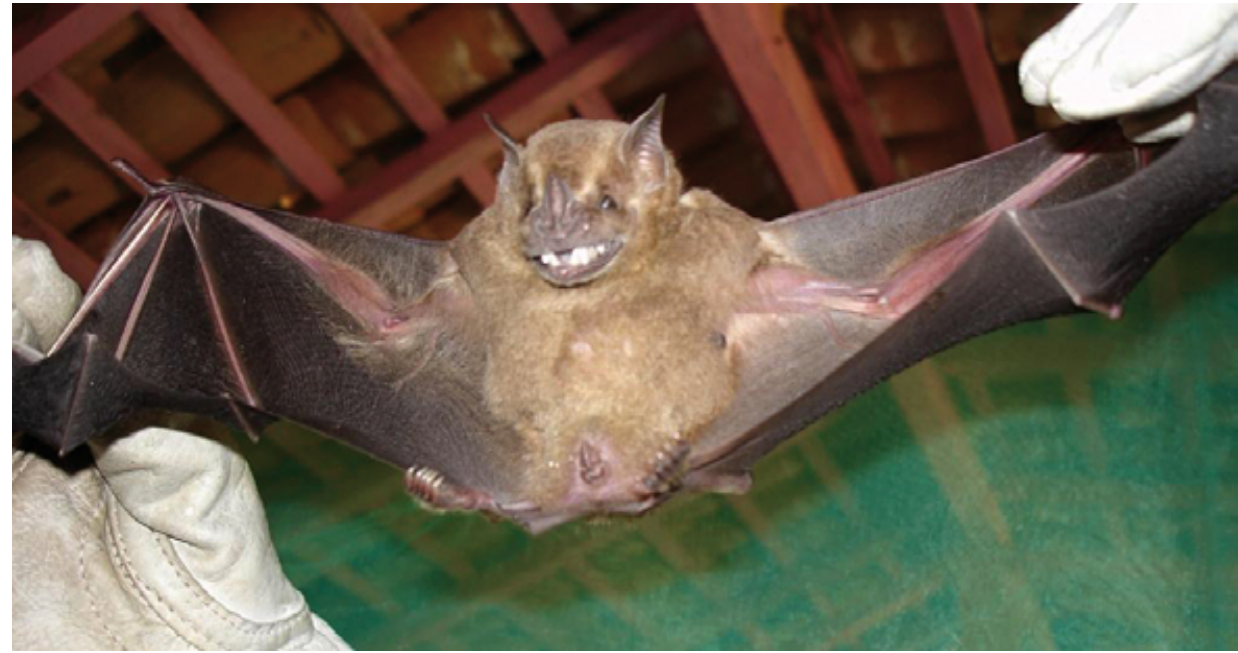

Figura 7.6: Artibeus planirostris proveniente de Cachoeira do Arari, PA.

Dentre os triatomíneos que compartilham o mesmo habitat que morcegos estão os insetos do gênero Cavernicola (C. lenti e $C$. pilosa), muito frequentes em cavernas, e dos gêneros Panstrongylus e Rhodnius encontrados em ocos de árvores. Rhodnius prolixus mantidos confinados com Carollia perspicillata, Glossophaga soricina e Desmodus rotundus foram capazes de realizar repastos sanguíneos completos, o que sugere que essa via também possa ser efetiva para a transmissão do parasito (Thomas et al. 2007). A transmissão congênita de $T$. cruzi foi recentemente descrita em Molossus molossus e proposta como outra importante via de disseminação do parasito na natureza (Añez et al. 2009), contrastando com as observações realizadas em primatas e marsupiais (Jansen et al. 1994, Lisboa et al. 2004). Estes dados, aparentemente contraditórios, apenas refletem a extrema complexidade do ciclo de transmissão de T. cruzi na natureza.

Um levantamento em 93 morcegos capturados em diferentes regiões do Brasil mostrou que $15 \%$ deles, incluídos em quatro diferentes famílias (Molossidae, Noctilionidae, Phyllostomidae e Vespertilionidae), apresentaram hemocultivos positivos para T. cruzi (Lisboa et al. 2008). A maioria (80\%) dos isolados derivaram da espécie generalista Phyllostomus hastatus, que é capaz de se infectar tanto ingerindo triatomíneos como pequenos mamíferos infectados. A família Phyllostomidae é a mais prevalente no Brasil, representando $57 \%$ das espécies de morcegos e sua alta prevalência de infecção aponta para a importância destes mamíferos na dispersão do parasito na natureza. Molossus molossus, encontrado em diferentes ambientes e tipicamente associado às habitações humanas e cidades, é outra espécie frequentemente encontrada infectada por T. cruzi. Não há associação descrita entre quirópteros e sub-populações de $T$. cruzi e todos os genótipos do parasito já foram descritos nesses mamíferos.

\section{Ordem Artiodactyla}

Uma interessante situação é representada pelo porco monteiro, forma feral (que retornou ao ambiente silvestre) do porco doméstico (Sus scrofa) no Pantanal brasileiro. Esses animais já foram encontrados infectados com o genótipo TCl de T. cruzi e apontados como importantes hospedeiros mantenedores do parasito na natureza (Herrera et al. 2008a). No mesmo estudo, duas 
espécies simpátricas de javalis (Tayassu tajacu e T. pecari) mostraram-se expostas ao ciclo de transmissão do parasito, como evidenciado pela presença de anticorpos anti-T. cruzi no soro desses animais. Em relação aos porcos domésticos (Figura 7.7), esses animais podem ser atrativos a triatomíneos, especialmente as espécies do gênero Panstrongylus, como observado em algumas áreas da região Amazônica (Valente et al. 1998). Apesar de estarem expostos ao ciclo de transmissão, há poucos relatos disponíveis de isolamento de parasitos em porcos domésticos (Salazar-Schettino et al. 1997, Valente et al. 1998) e seu papel como reservatório ainda precisa ser mais bem estudado. A exposição desses animais ao parasito em áreas peridomésticas e a possibilidade de diagnosticar a infecção através de exames sorológicos, mostram que esses animais também podem atuar como sentinelas em programas de vigilância e controle (Roque \& Jansen 2008).

O limitado número de estudos em caprinos sugere que o papel desempenhado por esses mamíferos peri-domésticos na transmissão do T. cruzi é apenas secundário, ape-

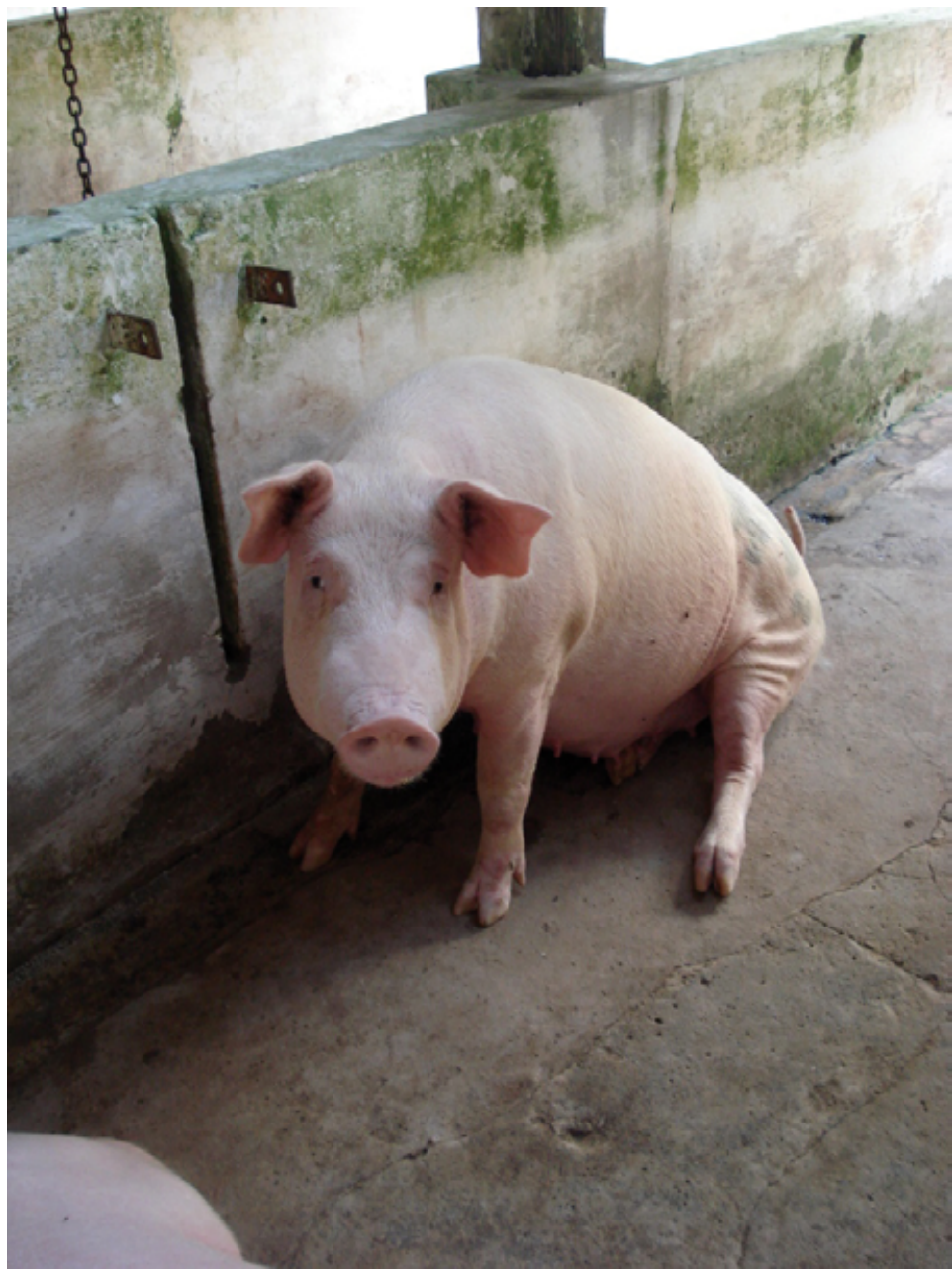

Figura 7.7: Sus scrofa (porco doméstico) proveniente de Abaetetuba, PA.

sar de estarem bastante expostos ao parasito (Noireau et al. 2009). Nunca foram descritas altas parasitemias em animais naturalmente infectados e o diagnóstico da infecção foi realizado apenas por métodos moleculares muito sensíveis (reação em cadeia da polimerase - PCR) ou métodos sorológicos indiretos (reação de imunofluorescência indireta - RIFI) (Rozas et al. 2007). Isolamento de $T$. cruzi em caprinos através de xenodiagnóstico e hemocultivo foi obtido apenas de animais experimentalmente infectados (Fernandes et al. 1994). 